HYPOTHESIS

\title{
Is rheumatoid arthritis disappearing?
}

T Uhlig, T K Kvien

Ann Rheum Dis 2005;64:7-10. doi: 10.1136/ard.2004.023044

During the past decades a number of studies have examined the incidence of rheumatoid arthritis (RA) in different geographical settings and at different times. Some studies from the 1970s and 1980s reported a higher incidence of RA than seen during recent years, where reported incidence numbers seems to have flattened out at a lower level. Besides a real time dependent decline of RA incidence, changing methodology in classification may be an equally important explanation. Today we may assume that annually 25-50 people from a population of 100000 will develop typical RA.

See end of article for authors' affiliations

.....................

Correspondence to:

Dr T Uhlig, Department of Rheumatology,

Diakonhiemmet Hospital, N-0319 Oslo, Norway;

till.uhlig@nrrk.no

Accepted 6 July 2004 Published Online First 29 July 2004
$\mathrm{R}$ ecent studies on the incidence of rheumatoid arthritis (RA) have rather consistently obtained a prevalence of between 0.5 and $1.0 \%,{ }^{12}$ and an annual incidence of around 2550 new cases per 100000 at risk. ${ }^{3}$ Much attention has been paid to epidemiological data demonstrating reduced life expectancy in $\mathrm{RA}^{5}$ and describing the considerable burden of RA, both for the individual and for society. Some studies indicated higher incidences of RA than seen during recent years. ${ }^{6-10}$ Thus, it is reasonable to ask whether there is a true decline in the incidence of RA.

At least three explanations are possible for these findings on incidence over time. Either the different results may be related to the use of varying methodology across different studies, or there are real geographical or ethnic differences in disease occurrence, or there is an effect of time.

\section{METHODOLOGICAL ISSUES}

It is reasonable to believe that different research approaches may give different results. Repeated surveys were used in the biennial examinations of the 4000 Pima or Tohono-O'odham Indians during the period 1965-90. ${ }^{11}$ Among nearly 3000 subjects, 78 incident cases of RA were identified over a period of 25 years. In Hiroshima and Nagasaki, 16000 survivors underwent biennial examinations from 1958 to 1964. Rheumatologists confirmed 23 new cases of RA, which yields an annual incidence of 110 women and 70 men per $100000 .{ }^{12}$ It is difficult to repeat surveys to assess trends in incidence because this would require at least three surveys.

A second technique examines case records in a fixed area. The Oslo RA register was established by identifying patients with a residential address in a well defined geographic area by retrospective record review in the two rheumatology departments in the county. ${ }^{2}$ The register has been shown to have a completeness of $85 \% .^{13}$ The number of new cases with RA (1987 American College of Rheumatology (ACR) criteria) with disease onset during 1988-93 was 550, with an incidence of 36/100 000 in women and 14/ 100000 in men. ${ }^{4}$ During the period 1950 to 1974 records from citizens in Rochester, mainly treated in the Mayo clinic, were reviewed. ${ }^{14}$ Over the first 25 years 521 cases were identified fulfilling the 1958 ARA criteria, giving an average annual incidence of 66 women and 28 men per $100000 .^{14}$

\section{"Several methods of assessing incident RA exist, and all have advantages and disad- vantages"}

Prospective notification is in many ways the ideal approach. In Seattle, Washington, incident female patients with RA aged 18-64 were identified from a group of members of a health maintenance organisation ( $15 \%$ of the population). The study personnel were contacted by rheumatologists, internists, and family physicians. The incidence of RA in women was found to be 24 per $100000 .{ }^{15}$ The Norfolk Arthritis Register in the United Kingdom is also based on prospective notification. General practitioners are asked to notify to the register all patients with inflammatory polyarthritis in a denominator population of 485000 . For patients with disease onset between 1990 and 1991 the incidence was found to be 36/100 000 in women and $14 / 100000$ in men, ${ }^{16}$ which is the same as the findings in the Oslo RA register. ${ }^{4}$

All these different methods for assessment of incident RA cases have their advantages and limitations. Repeated surveys give the most complete coverage of the population. Repeated surveys have the least problems in standardisation, but repetitive survey, are costly and may miss cases developing and remitting, deaths, or subjects moving in or out of the catchment area between the surveys. Retrospective record reviews are inexpensive, easy and feasible if records are comprehensive and regularly maintained and information on the items of the classification criteria is accessible. However, diseased subjects in the catchment population who do not attend the chosen clinic will not be retrieved. Prospective notification avoids standardisation difficulties when using the same observer. The completeness relies on continuous collaboration with the physicians who notify new cases as candidates for enrolment.

Several other methodological issues may also influence the results. ${ }^{17}$ The incidence figures greatly depend on the criteria used for case 
definition, the definition of time of onset, and on the possible delay before seeking medical help or referral. In the incidence study from Oslo a cumulative application of the 1987 ACR criteria for $\mathrm{RA}^{18}$ was used and a minimum of 2 years was allowed after referral for accumulation of classification criteria in order to register an incident RA case. Others ${ }^{19}$ have also recently advocated a similar procedure. A follow up study from the Norfolk Arthritis Register showed that the incidence of RA was 23\% higher in women and $42 \%$ higher in men if patients who were registered within 12 months from disease onset were given up to 5 years from onset of symptoms to cumulatively fulfil the individual items of the classification criteria. ${ }^{19}$

"Differentiation of RA from unspecified polyarthritis is difficult and may affect the incidence figures"

Early and aggressive treatment of RA has been supported during previous years. Such a practice may result in treatment even before patients have an established diagnosis. Some patients will thus not fulfil those items of the ACR classification criteria that are related to disease activity and severity and may never be classified with RA.

The qualifications and experience of health professionals classifying the patients also need to be considered. One extreme approach is to use self reported diagnoses, which has been shown to be clearly unreliable. ${ }^{13}$ A possible shift in incidence of RA might be due to a different perception of RA and differential diagnoses by the classifying doctor. ${ }^{6}$ The differentiation of RA from unspecified polyarthritis ${ }^{20}$ represents a typical clinical challenge. In two recent studies on the

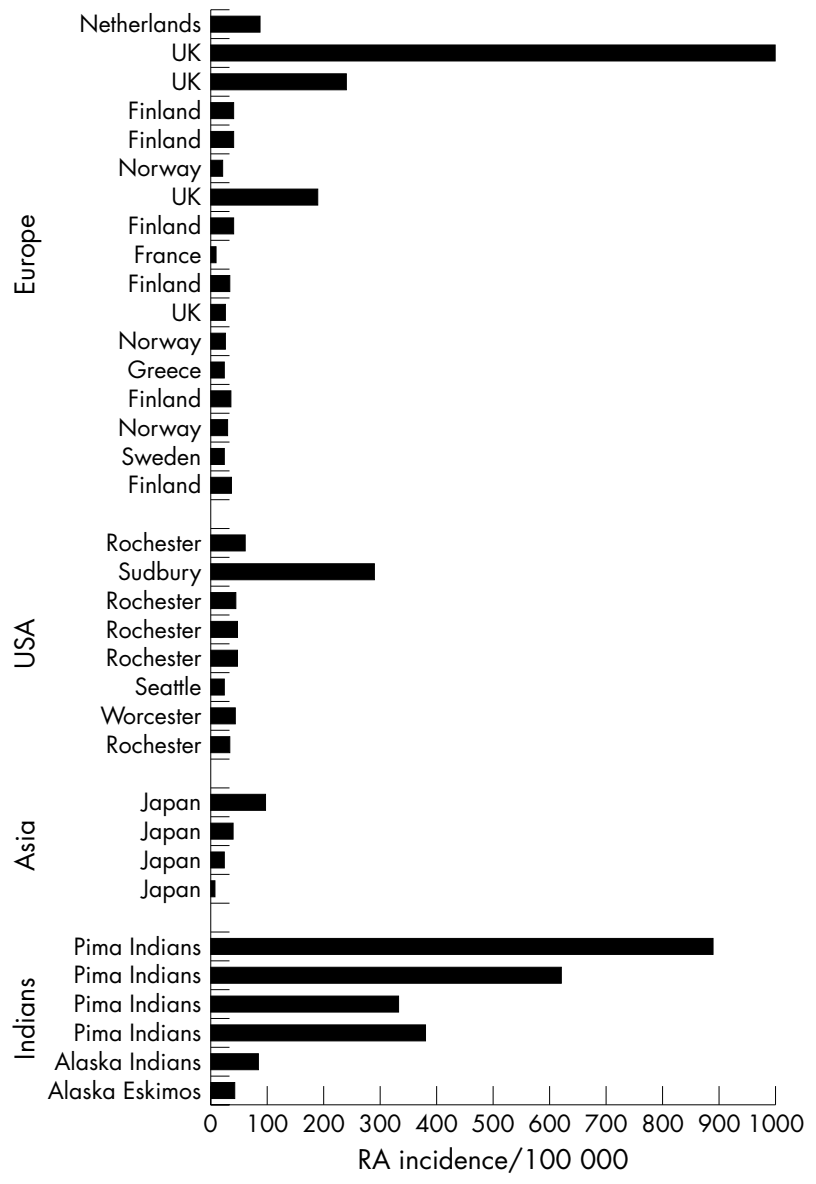

Figure 1 Geographic regions and incidence of RA. incidence of inflammatory joint diseases only about one out of seven patients in Kuopio, Finland, ${ }^{21}$ and one of four patients in southern Sweden ${ }^{22}$ presenting with inflammatory arthritis had RA according to the 1987 ACR criteria.

Factors related to left and right censorship may also contribute to wrong numbers. ${ }^{23}$ Left censorship in longitudinal studies refers, for example, to the potential bias introduced when patients are recruited at some stage after disease onset, if they die before recognition of the disease, or if patients are being treated in other healthcare systems. This underestimation of RA cases in the Oslo RA register has been suggested to be around $15 \%$, based on the results of a population survey. ${ }^{13}$ Right censorship relates to the potential loss of patients caused by follow up bias, such as death. The disease could be self limiting or have been successfully treated, removing the need for participation in follow up by the patient. Those items in the 1987 ACR classification criteria for $\mathrm{RA}^{18}$ not directly related to clinical joint findings (erosions, rheumatoid factor, rheumatoid nodules) may lead to a delay in obtaining the final diagnosis. On the other hand, overdiagnosis of RA including other inflammatory arthropathies or generalised osteoarthritis represents another challenge.

\section{INFLUENCE OF GEOGRAPHICAL FACTORS}

Figure 1 clearly indicate disparate findings across studies. Despite all the methodological uncertainties it is apparent that American Indians have a clearly higher incidence of RA than other populations in North America and Europe ${ }^{74}$ (fig 1).

\section{INFLUENCE OF TIME DEPENDENT FACTORS}

To further explore secular trends important studies examining the incidence of RA are summarised in table 1. Incidence was then plotted against time, using a logarithmic scale for incidence (fig 2). The bubble size corresponds to the total number of new cases identified in each study. The last year of observation was plotted if several consecutive years were studied. Inspection of the depicted studies suggests a secular decline of RA incidence during the 1970s. The curve then flattens out during the 1980s without consistent further decline. By inspection, discrepancies between studies also seem to be less.

Repeated studies within the same geographic regions have also supported the proposal that the incidence of RA is declining $^{6-11}$ (fig 1), and this trend was more marked in women. ${ }^{9}$ Results from the incidence studies performed in Rochester showed that the incidence of RA declined from 83 women per 100000 in the period 1955-1964 to 40 for the period 1985-1994, while the reduction for men was only from 37 to 26 per $100000 .{ }^{9}$ However, a linear declining trend was not observed, which might have been expected with a true decline in disease occurrence. Data from Finland have also indicated a minor decline in RA during the $1980 \mathrm{~s}^{10}{ }^{10}$ but a stable RA incidence in the population examined in $1990^{25}$ and $1995 .{ }^{26}$ Incidence rates based on only 16 incident RA cases in a Japanese district between 1965 to $1996^{8}$ must be interpreted carefully, but the declining incidence from 39/100 000 in the first (1965-75), to $24 / 100000$ in the second (1975-85) to 8/100 000 during the third decade (1985-96) of the observation period corroborates results of other studies that have examined RA incidence over several decades. In Pima Indians a fall in the incidence of RA has been demonstrated by Jacobsson et al over a 25 year period from 1965-1990. ${ }^{7}$

If there is a birth cohort effect successive generations may have been less likely to develop RA. ${ }^{27}$ Some studies have also suggested a shift in the incidence towards higher age. ${ }^{25} 28$ Age-specific peaks for birth cohorts have been demonstrated $^{29}$ and a reduced incidence and a possible shift in 


\begin{tabular}{|c|c|c|c|c|}
\hline Author & $\begin{array}{l}\text { Year } \\
\text { published }\end{array}$ & Period & Region & $\begin{array}{l}\text { Incidence/ } \\
100000\end{array}$ \\
\hline Den Oudsten ${ }^{32}$ & 1968 & $1949-63$ & Rotterdam, The Netherlands & 87 \\
\hline Kato $^{12}$ & 1971 & $1958-64$ & Japan & 97 \\
\hline Doran 9 & 2002 & $1955-64$ & Rochester, USA & 61 \\
\hline O'Sullivan ${ }^{33}$ & 1972 & 1968 & Sudbury, USA & 290 \\
\hline Lawrence $^{34}$ & 1977 & $1959-68$ & Leigh/Wensleydale, UK & 1000 \\
\hline Hochberg $^{6}$ & 1990 & 1970-72 & UK & 240 \\
\hline Jacobsson ${ }^{7}$ & 1994 & $1966-73$ & Pima Indians & 890 \\
\hline Doran 9 & 2002 & $1965-74$ & Rochester, USA & 47 \\
\hline Linos $^{14}$ & 1980 & $1950-74$ & Rochester, USA & 44 \\
\hline Isomäki ${ }^{35}$ & 1978 & $1974-75$ & Heinola, Finland & 42 \\
\hline Shichikawa $^{8}$ & 1999 & $1965-75$ & Kamitonda, Japan & 39 \\
\hline Kaipiainen-Seppänen $^{10}$ & 1996 & 1980 & Finland & 38 \\
\hline $\mathrm{Gran}^{36}$ & 1986 & $1969-81$ & Lillehammer, Norway & 21 \\
\hline Jacobsson ${ }^{7}$ & 1994 & $1974-82$ & Pima Indians & 620 \\
\hline Hochberg ${ }^{6}$ & 1990 & $1981-82$ & UK & 190 \\
\hline Boyer $^{37}$ & 1991 & $1970-84$ & Alaska southeast Indians & 84 \\
\hline Boyer $^{37}$ & 1991 & $1970-84$ & Alaska Yupik Eskimos & 42 \\
\hline Del Puente ${ }^{24}$ & 1989 & 1969-84 & Pima Indians & 333 \\
\hline Doran ${ }^{9}$ & 2002 & 1975-84 & Rochester, USA & 46 \\
\hline Shichikawa $^{8}$ & 1999 & 1975-85 & Kamitonda, Japan & 24 \\
\hline Kaipiainen-Seppänen $^{10}$ & 1996 & 1985 & Finland & 39 \\
\hline Dugowson $^{15}$ & 1991 & 1987-89 & Seattle, USA & 24 \\
\hline Guillemin $^{38}$ & 1994 & $1986-89$ & Lorraine, France & 9 \\
\hline Jacobsson ${ }^{7}$ & 1994 & $1983-90$ & Pima Indians & 380 \\
\hline $\mathrm{Chan}^{39}$ & 1993 & $1987-90$ & Worcester, USA & 42 \\
\hline Symmons $^{16}$ & 1994 & 1990 & Norfolk, UK & 26 \\
\hline Kaipiainen-Seppänen ${ }^{10}$ & 1996 & 1990 & Finland & 33 \\
\hline Uhlig $^{4}$ & 1998 & 1988-93 & Oslo, Norway & 26 \\
\hline Doran' & 2002 & $1985-94$ & Rochester, USA & 33 \\
\hline Drosos $^{3}$ & 1997 & 1987-95 & Northwest Greece & 24 \\
\hline Kaipiainen-Seppänen ${ }^{26}$ & 2000 & 1995 & Finland & 34 \\
\hline Shichikawa ${ }^{8}$ & 1999 & $1985-96$ & Kamitonda, Japan & 8 \\
\hline Riise $^{40}$ & 2000 & $1987-96$ & Troms, Norway & 29 \\
\hline Söderlin ${ }^{22}$ & 2002 & 1999-2000 & Kronoberg, Sweden & 24 \\
\hline Savolainen ${ }^{21}$ & 2003 & 2000 & Kuopio, Finland & 36 \\
\hline
\end{tabular}

incidence towards higher age must be sought in the environment. The most reasonable explanation for the decline in women may be exposure to the contraceptive pill, which clearly reduces the incidence of RA. ${ }^{30}$

\section{INCIDENCE LINKED TO DISEASE SEVERITY}

Many rheumatologists in their daily work find that patients attending rheumatology clinics today have, in general, less severe disease than 20-30 years ago. For healthcare planning it would be important to know if there is a real decline in the burden of the disease for both the individual person and for society.
Longitudinal outcome data from incident cases would help us to know whether RA is becoming milder. Unfortunately, data in this area of research are limited. In the Oslo RA register the prevalence of RA was found to be about $0.5 \%$, but only half of all patients had a disability level associated with reduced life expectancy, ${ }^{2}$ - that is, a modified Health Assessment Questionnaire score exceeding 1.5 (range 14). ${ }^{31}$ If managed in a setting offering comprehensive and aggressive treatment, $30-40 \%$ of these patients will develop clinically important disability due to RA within the first 35 years. About half of the patients also had reached clinically important levels of health status for psychosocial measures. ${ }^{4}$

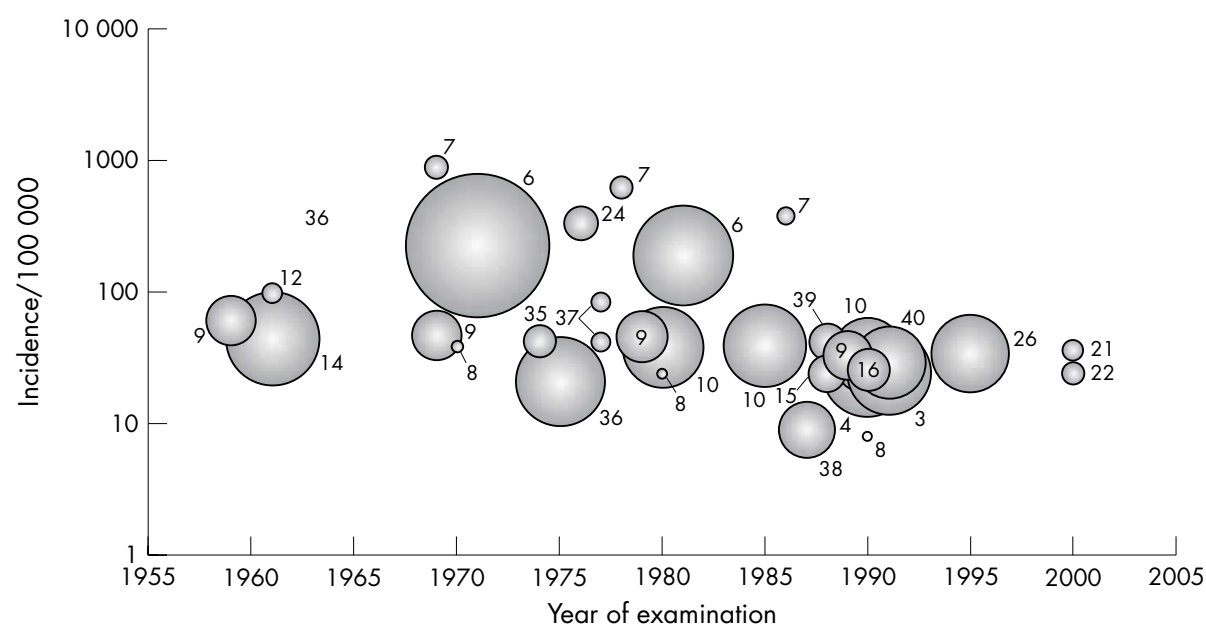

Figure 2 Secular incidence of RA. The bubble size corresponds to the total number of new cases in each study (middle year of observation period plotted, numbers indicate references). 


\section{CONCLUSIONS}

Present knowledge suggests that RA today occurs less often than reported several decades ago and that the incidence of RA today is lower than during the 1950s. This decline seems mainly to have occurred during the 1970s or early 1980s.

Changing methodology in classification and other methodological issues may be an equally important explanation besides a real time dependent decline of RA incidence. RA only represents a fraction of the spectrum of arthritides, and a high number of undifferentiated arthritides, especially, have been observed in recent surveys. Healthcare planners may assume that annually $25-50$ people from a population of 100000 will develop typical RA.

Future studies need to examine further trends in RA incidence and whether the observed shift in incidence towards higher age can be confirmed. Further, it will be important to healthcare planners to identify the proportion of patients with RA who will reach clinical levels of health requiring various health services.

\section{Authors' affiliations}

T Uhlig, T K Kvien, Department of Rheumatology, Diakonhjemmet Hospital, N-0319 Oslo, Norway

\section{REFERENCES}

1 Lawrence RC, Helmick CG, Arnett FC, Deyo RA, Felson DT, Giannini EH, et al. Estimates of the prevalence of arthritis and selected musculoskeletal disorders in the United States. Arthritis Rheum 1998;41:778-99.

2 Kvien TK, Glennås A, Knudsrød OG, Smedstad LM, Mowinckel P, Førre $\varnothing$. The prevalence and severity of rheumatoid arthritis in Oslo: results from a county register and a population survey. Scand J Rheumatol 1997;26:412-18.

3 Drosos AA, Alamanos I, Voulgari PV, Psychos DN, Katsaraki A, Papadopoulos I, et al. Epidemiology of adult rheumatoid arthritis in northwest Greece 1987-1995. J Rheumatol 1997;24:2129-33.

4 Uhlig T, Kvien TK, Glennås A, Smedstad LM, Forre $\varnothing$. The incidence and severity of rheumatoid arthritis, results from a county register in Oslo, Norway. J Rheumatol 1998;25:1078-84.

5 Pincus T, Callahan LF. Reassessment of twelve traditional paradigms concerning the diagnosis, prevalence, morbidity and mortality of rheumatoid arthritis. Scand J Rheumatol Suppl 1989;79:67-96.

6 Hochberg MC. Changes in the incidence and prevalence of rheumatoid arthritis in England and Wales, 1970-1982. Semin Arthritis Rheum 1990; 19:294-302.

7 Jacobsson LT, Hanson RL, Knowler WC, Pillemer S, Pettitt DJ, McCance DR et al. Decreasing incidence and prevalence of rheumatoid arthritis in Pima Indians over a twenty-five-year period. Arthritis Rheum 1994;37:1158-65.

8 Shichikawa K, Inoue K, Hirota S, Maeda A, Ota H, Kimura M, et al. Changes in the incidence and prevalence of rheumatoid arthritis in Kamitonda, Wakayama, Japan, 1965-1996. Ann Rheum Dis 1999;58:751-6.

9 Doran MF, Pond GR, Crowson CS, O'Fallon WM, Gabriel SE. Trends in incidence and mortality in rheumatoid arthritis in Rochester, Minnesota, over a forty-year period. Arthritis Rheum 2002;46:625-31.

10 Kaipiainen-Seppänen O, Aho K, Isomäki H, Laakso M. Incidence of rheumatoid arthritis in Finland during 1980-1990. Ann Rheum Dis 1996:55:608-11.

11 Jacobsson LT, Pillemer SR. What can we learn about rheumatic diseases by studying Pima Indians? J Rheumatol 1994;21:1179-82.

12 Kato H, Duff IF, Russell WJ, Uda Y, Hamilton HB, Kawamoto S, et al. Rheumatoid arthritis and gout in Hiroshima and Nagasaki, Japan. A prevalence and incidence study. J Chron Dis 1971;23:659-79.

13 Kvien TK, Glennås A, Knudsrød OG, Smedstad LM. The validity of selfreported diagnosis of rheumatoid arthritis: results from a population survey followed by clinical examinations. J Rheumatol 1996;23:1866-71.
14 Linos A, Worthington JW, O'Fallon WM, Kurland LT. The epidemiology of rheumatoid arthritis in Rochester, Minnesota: a study of incidence, prevalence, and mortality. Am J Epidemiol 1980;111:87-98.

15 Dugowson CE, Koepsell TD, Voigt LF, Bley L, Nelson JL, Daling JR. Rheumatoid arthritis in women. Incidence rates in group health cooperative, Seattle, Washington, 1987-1989. Arthritis Rheum 1991;34:1502-7.

16 Symmons DP, Barrett EM, Bankhead CR, Scott DG, Silman AJ. The incidence of rheumatoid arthritis in the United Kingdom: results from the Norfolk Arthritis Register. Br J Rheumatol 1994:33:735-9.

17 Silman A, Hochberg M. Epidemiology of the rheumatic diseases. Oxford: Oxford University Press, 1993.

18 Arnett FC, Edworthy SM, Bloch DA, McShane DJ, Fries JF, Cooper NS, et al. The American Rheumatism Association 1987 revised criteria for the classification of rheumatoid arthritis. Arthritis Rheum 1988;31:315-24.

19 Wiles N, Symmons DP, Harrison B, Barrett E, Barrett JH, Scott DG, et al. Estimating the incidence of rheumatoid arthritis: trying to hit a moving target? Arthritis Rheum 1999;42:1339-46.

20 Wolfe F, Ross K, Hawley DJ, Roberts FK, Cathey MA. The prognosis of rheumatoid arthritis and undifferentiated polyarthritis syndrome in the clinic: a study of 1141 patients. J Rheumatol 1993;20:2005-9.

21 Savolainen E, Kaipiainen-Seppänen O, Kröger L, Luosujärvi R. Total incidence and distribution of inflammatory joint diseases in a defined population: results from the Kuopio 2000 arthritis survey. J Rheumatol 2003;30:2460-8.

22 Söderlin MK, Börjesson O, Kautiainen $H$, Skogh T, Leirisalo-Repo M. Annual incidence of inflammatory joint diseases in a population based study in southern Sweden. Ann Rheum Dis 2002;61:911-15.

23 Silman A, Symmons D. Reporting requirements for longitudinal observational studies in rheumatology. J Rheumatol 1999;26:481-3.

24 Del Puente A, Knowler WC, Pettitt DJ, Bennett PH. High incidence and prevalence of rheumatoid arthrits in Pima Indians. Am J Epidemiol 1989;129:1170-8.

25 Kaipiainen-Seppänen O, Aho K, Isomäki H, Laakso M. Shift in the incidence of rheumatoid arthritis toward elderly patients in Finland during 1975-1990. Clin Exp Rheumatol 1996;14:537-42.

26 Kaipiainen-Seppänen O, Aho K. Incidence of chronic inflammatory joint diseases in Finland in 1995. J Rheumatol 2000;27:94-100.

27 Silman AJ. The changing face of rheumatoid arthritis: why the decline in incidence? Arthritis Rheum 2002;46:579-81.

28 Imanaka T, Schichikawa K, Inove K, Shimaoka Y, Takenaka Y, Wakitani S. Increase in age at onset of rheumatoid arthritis in Japan over a 30 year period. Ann Rheum Dis 1997:56:313-16.

29 Gabriel SE, Crowson CS, O'Fallon WM. The epidemiology of rheumatoid arthritis in Rochester, Minnesota, 1955-1985. Arthritis Rheum 1999;42:415-20

30 Doran MF, Crowson CS, O'Fallon WM, Gabriel SE. The effect of oral contraceptives and estrogen replacement therapy on the risk of rheumatoid arthritis: a population based study. J Rheumatol 2004;31:207-13.

31 Wolfe F, Kleinheksel SM, Cathey MA, Hawley DJ, Spitz PW, Fries JF. The clinical value of the Stanford Health Assessment Questionnaire Functional Disability Index in patients with rheumatoid arthritis. J Rheumatol 1988;15:1480-8.

32 den Oudsten SA, Planten O, Posthuma EPS. Longitudinal survey of RA in an urban district of Rotterdam. Excerpta Med Int Cong Series 1968;148:99-105.

33 O'Sullivan JB, Cathcart ES, Bolzan JA. Diagnostic criteria and the incidence of rheumatoid arthritis in Sudbury: population studies of the rheumatic diseases. Excerpta Med Int Cong Series 1968;148:109-13.

34 Lawrence JS. Rheumatism in populations. London: Heinemann, 1977:210-13.

35 Isomäki H, Raunio J, von Essen R, Hämeenkorpi R. Incidence of inflammatory rheumatic diseases in Finland. Scand J Rheumatol 1978:7:188-92.

36 Gran JT, Magnus J, Mikkelsen K, Nygaard H, Brath HK. The incidence of classical and definite rheumatoid arthritis in Lillehammer, Norway. Scand J Rheumatol 1986;15(suppl 59):7.

37 Boyer GS, Templin DW, Lanier AP. Rheumatic diseases in Alaskan Indians of the southeast coast: high prevalence of rheumatoid arthritis and systemic lupus erythematosus. J Rheumatol 1991;18:1477-84.

38 Guillemin F, Briancon S, Klein JM, Sauleau E, Pourel J. Low incidence of rheumatoid arthritis in France. Scand J Rheumatol 1994;23:264-8.

39 Chan KW, Felson DT, Yood RA, Walker AM. Incidence of rheumatoid arthritis in central Massachusetts. Arthritis Rheum 1993;36:1691-6.

40 Riise T, Jacobsen BK, Gran JT. Incidence and prevalence of rheumatoid arthritis in the county of Troms, northern Norway. J Rheumatol 2000;27:1386-9. 